\title{
Ankaferd blood stopper: Gastrointestinal kanamalarda yeni bir topikal hemostatik ajan
}

\section{The Ankaferd blood stopper: A novel topical hemostatic agent in gastrointestinal bleeding}

Hüseyin Sancar BOZKURT

Özel Tarsus Medikal Park Hastanesi, Gastroenteroloji Bölümü, Mersin

Gastrointestinal sistem kanaması ağızdan anal kanala kadar olan gastrointestinal alanın çeşitli patolojilerine bağlı olarak oluşur. Endoskopik, hemostatik ve farmakolojik tekniklere rağmen peptik ülsere bağlı mortalite halen \%5-\%10 civarndadır. Ankaferd blood stopper yeni ve başarılı bir topikal hemostatik ajandir. Ankaferd blood stopper ülkemizde yetişen Thymus vulgaris, Glycyrrhiza glabra, Vitis vinifera, Alpinia officinarum, and Urtica dioica bitkilerinin karışımından oluşmaktadır. Özellikle yönetimi zor olan gastrointestinal kanamalarda başarısı çeşitli çalışmalarla kanıtlanmıştır.

Anahtar kelimeler: Ankaferd blood stopper, gastrointestinal kanama, hemostaz

\section{GİRISS}

Gastrointestinal sistem (GIS) kanaması ağıdan anal kanala kadar olan gastrointestinal alanın çeşitli patolojilerine bağlı olarak oluşur. Endoskopik, hemostatik ve farmakolojik tekniklere rağmen peptik ülsere bağlı mortalite halen \%5-\%10 civarındadır (1). Malign lezyonlara bağlı alt GIS kanama 60 yaş üzerinde en sık 3. kanama sebebidir (2). Ankaferd blood stopper (ABS) ülkemizde yetişen Thymus vulgaris, Glycyrrhiza glabra, Vitis vinifera, Alpinia officinarum, ve Urtica dioica bitkilerinin karışımından oluşan yeni nesil bir topikal hemostatik ajandir (3).

\section{OLGU SUNUMU}

Kliniğimize 71 yaşında evre 4 prostat kanseri tanısı ve radyoterapiye bağlı pansitopenisi (platelet: $50.000 \mathrm{~K} / \mathrm{ul}$ ) olan erkek hasta alt GIS kanama ve 59 yaşında koroner arter hastalığı nedeniyle antiagregan tedavi alan erkek hasta üst GIS kanama ile yatırıldı. Her iki hastaya da hemodinamik stabilizasyon sonrası endoskopi yapıldı. Prostat ca tanısı olan hastanın kolonoskopisinde rektumda aktif kanama gösteren malign lezyon üzerine standart tek lümenli skleroterapi iğnesi ile
Gastrointestinal bleeding refers to any hemorrhage ascribed to the pathologies of the gastrointestinal tract, extending from the mouth to the anal canal. Despite the recent improvements in the endoscopic, hemostatic, and adjuvant pharmacologic techniques, the reported mortality for peptic ulcer bleeding is still around 5\%-10\%. The Ankaferd blood stopper, a novel topical hemostatic agent, is a standardized mixture of the plants Thymus vulgaris, Glycyrrhiza glabra, Vitis vinifera, Alpinia officinarum, and Urtica dioica found in Anatolia, Turkey. Ankaferd blood stopper offers a successful option, specifically for "difficult-to-manage" situations, as evidenced by the data presented in several studies.

Key words: Ankaferd blood stopper, gastrointestinal bleeding, hemostasis endoskopisinde bulbus ön duvarda sızıntı şeklinde kanama gösteren ülser üzerine 5 cc ABS uygulandı (Resim 2). Her iki hastada da kanama kontrolü sağlandı ve takiplerinde herhangi bir komplikasyon gelişmedi.

\section{TARTIŞMA}

ABS, kanama durumunda çok hızlı bir şekilde enkapsüle protein ağı oluşturup saniyeler içinde eritrosit agregasyonuna yol açmaktadır (4). ABS, yönetimi zor olan gastrointestinal kanamalarda da kullanılabilen uygulanımı kolay, etkili, maliyeti düşük ve yerli bir üründür (5).

ABS yeni nesil bir topikal hemostatik ajandır (3). ABS, kanama durumunda çok hızlı bir şekilde enkapsüle protein ağı oluşturup saniyeler içinde eritrosit agregasyonuna yol açmaktadır (4). ABS, yönetimi zor olan ve çeşitli etiyolojilere bağlı gelişen akut gastrointestinal kanamalarda kullanılabilen, standart skleroterapi iğnesi ile uygulanımı kolay, hızlı etkili, maliyeti düşük ve yerli bir üründür (5). 


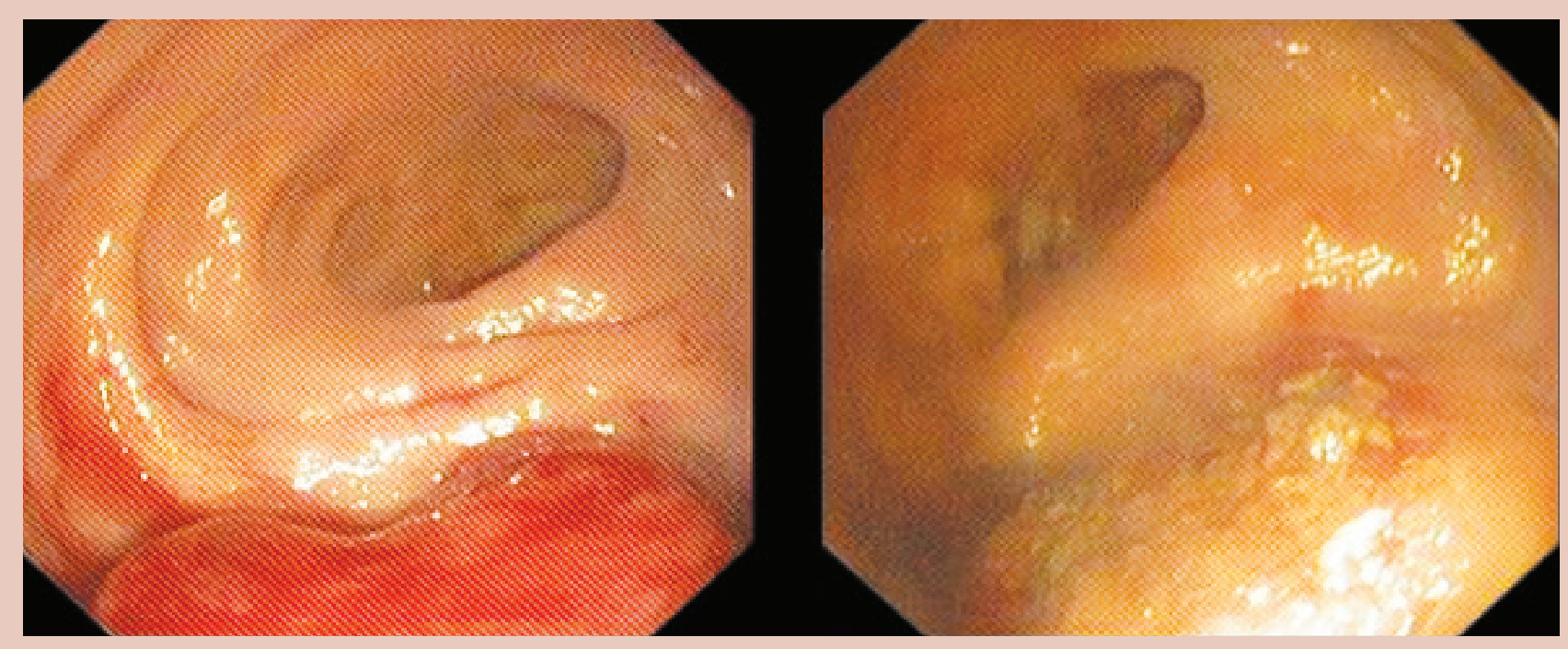

Resim 1. Rektumda kanamalı malign lezyon ve Ankaferd uygulama sonrası

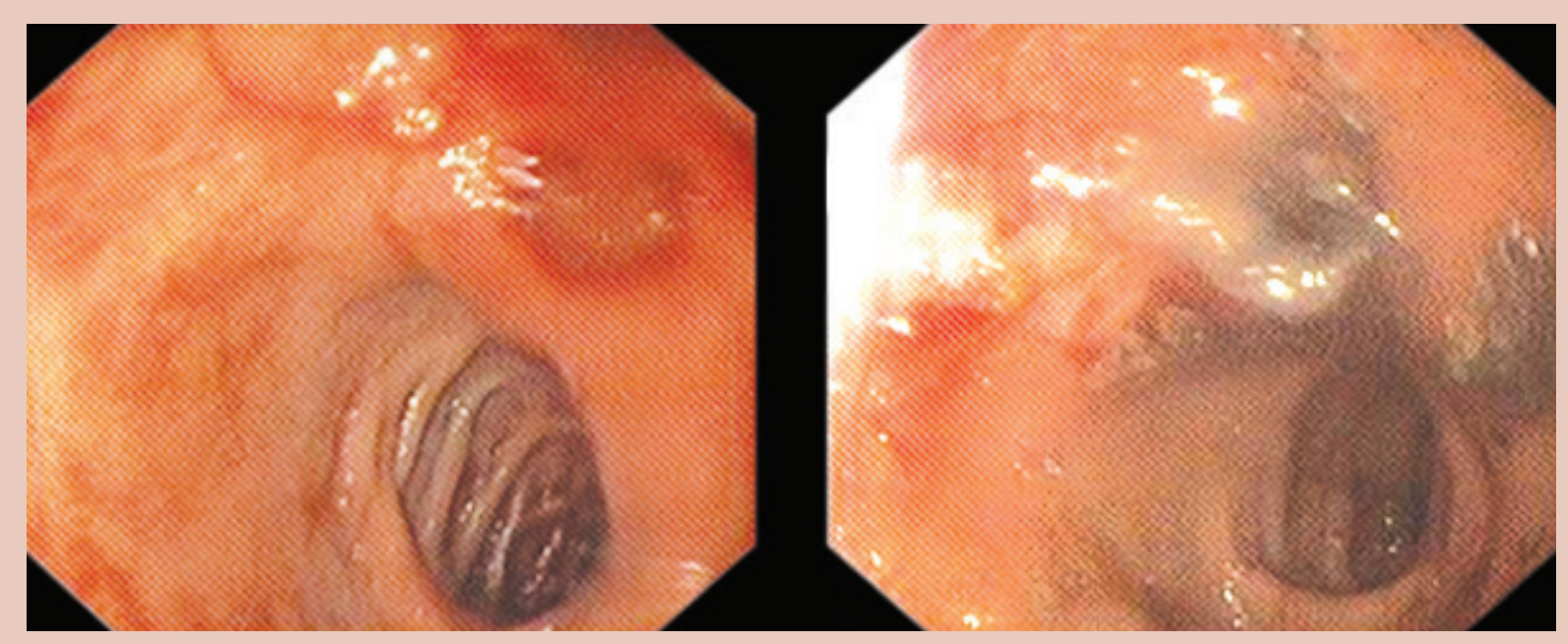

Resim 2. Bulbus ön duvarda sızıntı kanamalı ülser ve Ankaferd uygulama sonrası

\section{KAYNAKLAR}

1. Beyazit Y, Kekilli M, Haznedaroglu IC, et al. Ankaferd hemostat in the management of gastrointestinal hemorrhages. World J Gastroenterol 2011;17:3962-70.

2. Raphaeli T, Menon R. Current treatment of lower gastrointestinal hemorrhage. Clin Colon Rectal Surg 2012;25:219-27.

3. Gungor Gl, Goktepe MH, Biyik M, et al. Efficacy of Ankaferd blood stopper application on non-variceal upper gastrointestinal bleeding. World J Gastrointest Endosc 2012;4:556-60.
4. Goker H, Haznedaroglu IC, Ercetin S, et al. Haemostatic actions of the folkloric medicinal plant extract, Ankaferd Blood Stopper. J Int Med Res 2008;36:163-70.

5. Kurt M, Akdogan M, Ibis M, Haznedaroglu IC. Ankaferd blood stopper for gastrointestinal bleeding. J Invest Surg 2010;23:239. 